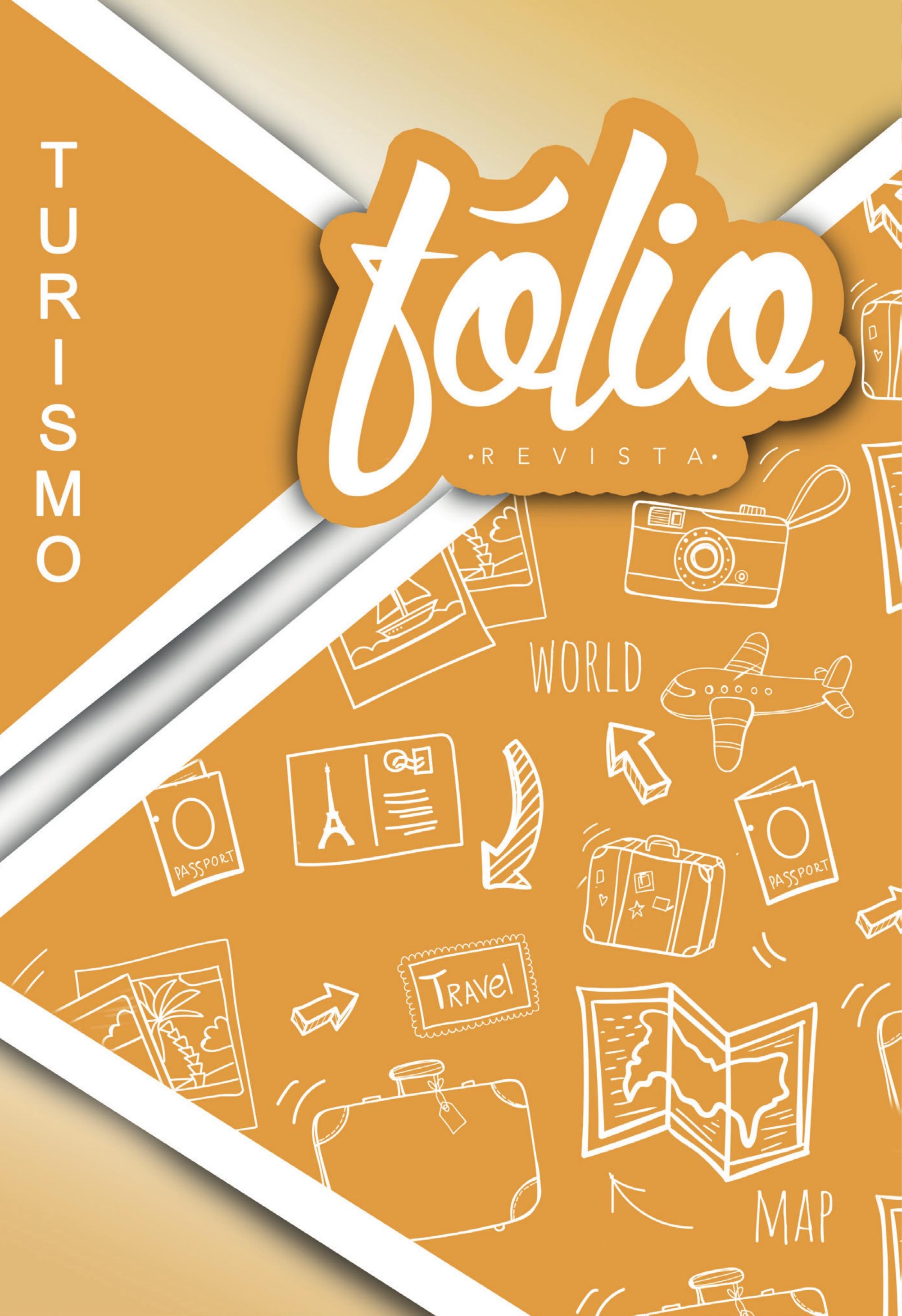




\title{
A qualidade da oferta de alimentação a celíacos: um estudo de caso no Rio Grande do Sul
}

\section{The quality of food supply for celíacos:}

a case study in Rio Grande do Sul

\author{
Ana Marta Cavalheiro Kerber \\ Guilherme Bridi
}

\section{Resumo}

Este trabalho aborda questões associadas à qualidade da oferta a alimentação de pessoas com intolerância ao glúten. O objetivo deste estudo foi o de identificar de que forma os portadores de DC avaliam a oferta de restaurantes para sua restrição alimentar no tocante às variáveis: preço, qualidade e variedade dos pratos, confiabilidade das informações e atendimento. A pesquisa foi aplicada através de formulário virtual com indivíduos pertencentes ao Grupo do Facebook de uma Associação específica para este público. Após a aplicação do instrumento com os respondentes, os dados levantados assinalam que a oferta de alimento sem glúten pelos restaurantes ainda é restrita, sendo que igualmente foi constatada a ocorrência de temor por parte dos portadores de DC pela contaminação cruzada, a partir da falta de preparo destes estabelecimentos para produzir pratos livres dessa contaminação.

Palavras-chave: Restaurantes. Portadores Doença Celíaca. Glúten. Restrição Alimentar.

\section{Abstract}

This work addresses issues related to the quality of food supply of people with gluten intolerance.. he objective of this study was to identify the way in which CD patients evaluate the supply of restaurants for their food restriction in relation to the variables: price, quality and variety of dishes, reliability of information and service. The research was applied through a virtual form with individuals belonging to the Facebook Group from a specific Association. After the application of the instrument with the respondents, the collected data indicate that the gluten-free food supply in the restaurants is still restricted, and it has also been verified the fear of the CR carriers by cross contamination, due to the lack of preparation of these establishments to produce dishes free of this contamination.

Keywords: Restaurants. Carriers Celiac Disease. Gluten. Food restriction. 


\section{Introdução}

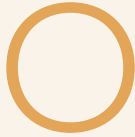

presente trabalho possui como tema central realizar uma análise junto aos membros de uma Associação específica, bem como a identificação, à partir do ponto de vista desse grupo de pessoas, dos pontos fortes e fracos dos restaurantes oferecidos no que compete às variáveis: preço, qualidade e variedade dos pratos, confiabilidade das informações e atendimento. A pesquisa foi executada entre os meses de setembro e outubro de 2017 com realização de um questionário online e registrando a coleta de dados baseada na resposta de 43 sujeitos portadores da restrição alimentar ao glúten.

O problema de pesquisa propõe responder algumas questões, sendo elas: Partindo do pressuposto de que a intolerância ao glúten consiste como uma das doenças mais comuns e de mais fácil de detecção nos dias de hoje, pergunta- se. Como os portadores de DC avaliam a oferta dos cardápios de restaurantes para sua restrição alimentar no tocante às variáveis: preço, qualidade e variedade dos pratos, confiabilidade das informações e atendimento? Quais os pontos fortes e fracos desse processo de oferta alimentar específica?

O objetivo geral consiste em identificar de que forma os portadores de DC avaliam a oferta dos cardápios de restaurantes para sua restrição alimentar no tocante às variáveis: preço, qualidade e variedade dos pratos, confiabilidade das informações e atendimento.

Como objetivos específicos, têm- se, identificar, a partir da visão dos respondentes da pesquisa, as principais fragilidades e fortalezas da prestação de serviços em A\&B para dietas com restrição ao glúten, caracterizar o nível de confiança dos usuários sobre estes serviços e propor possíveis melhorias acerca do cenário analisado.

Tensionando o foco da discussão para alimentação, essa realidade parece evidenciar-se ainda mais, no sentido de que, gradativamente, os avanços na medicina, os quais possibilitaram o mapeamento e identificação das mais diversas restrições alimentares. Isso posto, considera-se que, a adequação dos estabelecimentos que prestam serviços de $A \&$ B constitui-se como um importante fa- tor de inovação na prestação de serviços.

Assim sendo, ao direcionarmos o enfoque deste trabalho para o público portador da Doença celíaca, percebe-se que o referido assunto vem sendo abordado pelo motivo de que a Doença Celíaca (DC), é causadora de um grande mal-estar. A enfermidade é autoimune afetando um em cada cem adultos, segundo dados da Associação de Celíacos do Brasil (ACELBRA'). Percebe-se igualmente que o número de portadores quadruplicou nas últimas décadas. Ainda não há cura para a DC, sendo que o único meio para combater essa restrição consiste numa dieta seguida a risca sem o glúten, não sendo ingerido nem mesmo uma pequena quantidade.

A autora deste trabalho traz a importância do assunto que uma vez feito o diagnóstico as pessoas precisam se organizar em um cardápio abolindo de vez o glúten, sendo os restaurantes referidos se organizar e investir para atender essa parte da população.

\section{Referencial teórico}

\section{Cardápios}

Conforme os apontamentos de Cândido e Viera (2002), o cardápio consiste na listagem dos pratos que compõem uma refeição. $\bigcirc$ processo de planejamento de um cardápio não deve contemplar apenas a preparação do almoço ou jantar, mas também de proporcionar uma combinação de alimentos que forneçam todos os nutrientes necessários para a subsistência de nosso organismo.

Nessa direção, para Cândido (2010), compreende-se que cardápio de um determinado restaurante necessita se identificar tanto com o perfil do cliente, como também do mercado consumidor em potencial.

Em complemento a isso, Cândido (2010) aponta que

\footnotetext{
1 ASSOCIAÇÃO DE CELÍACOS DO BRASIL (ACELBRA). Associação dos Celíacos do Brasil - ACELBRA. [S.I.]. 2014. Disponível em: < http://www.acelbra.org.br/2004/index.php > Acesso em: 21 maio. 2017.
} 
Na elaboração do cardápio devem ser considerados os hábitos de alimentação, o nível social, o poder aquisitivo, a idade, o sexo, o estado civil, atividade profissional, bem como, a origem e a nacionalidade dos clientes/frequentadores habituais e potenciais. Para a avaliação da preferência, desejos e receptividade dos clientes quanto o cardápio é recomendável a realização de pesquisa de mercado ou consulta aos clientes, ao público e os funcionários que têm contato com o público. (CÂNDIDO, 2010, p.151).

Assim sendo, conforme expõem Cândido e Viera (2002), no processo de elaboração de um cardápio, muitos itens necessitam ser levados em consideração, sendo eles:

\section{a) valor qualitativo dos alimentos;}

Deve-se levar em consideração a inclusão de alimentos que apresentem valores nutritivos diferenciados, ricos em proteínas, hidratos de carbono, gorduras, vitaminas, sais minerais, água e celulose.

\section{b) valor Quantitativo dos alimentos;}

A quantidade dos alimentos dispostos em um cardápio deve ser suficiente para promover uma satisfação das necessidades de reposição de energia de nosso organismo, bem como de manutenção e renovação do corpo.

\section{c) condições econômicas;}

Obviamente, o cardápio deve estar em consonância com as condições econômicas da família ou empresa. Para isso, se faz necessário aprofundar os conhecimentos sobre nutrição, a fim de promover possíveis substituições de alimentos que tenham valor mais elevado por outros mais econômicos que, no entanto, possam oferecer valores nutricionais semelhantes.

\section{d) hábitos alimentares;}

Deve-se atender igualmente ao número e horário das refeições adequadas às condições dos sujeitos. Este número de refeições pode variar de 3 a 5. Como hábito, pode-se reforçar a primeira refeição do dia com alimentos ricos em proteína (ovos, queijos e demais laticínios), bem como com frutas cítricas a fim de preparar melhor o organismo para enfrentar o dia cotidiano.

\section{e) variedade e harmonia.}

Este é considerado um dos itens de maior importância no processo de elaboração de um cardápio. Corroborando com essa ideia, Cândido e Viera (2002) consideram que um bom cardápio necessita apresentar uma variedade nos alimentos, seja em sabor, consistência, cor e temperatura.

Entre as regras básicas de elaboração de um cardápio variado, pode-se considerar que o mesmo deve primar pela composição de 4 elementos principais: peixes, carnes, legumes e frutas.

Não deve haver repetições de um alimento em um mesmo cardápio. Assim, se um cardápio servir purê de batatas como acompanhamento, esse alimento não deverá ser servido em outros itens que compõem o cardápio.

As modalidades de cozimento também necessitam ser distintas, não devendo então haver 2 pratos cremosos nem 2 pratos assados. Dessa forma, se o peixe for servido assado, a carne deverá ser servida frita, cozida ou grelhada

$\mathrm{Na}$ sequência do servir, deve-se iniciar com iguarias de sabor suave para depois oferecer os pratos de sabores mais fortes. Essa combinação também valerá para a composição dos vinhos oferecidos em um cardápio.

O processo de planejamento e elaboração de um cardápio necessita contar com profissionais aptos a desenvolver de forma efetiva essa etapa. Para que isso se torne possível, Teichmann (2000) considera que antes é preciso ter conhecimento dos vários serviços que compõem uma refeição.

A ordem dos serviços utilizados varia gradativamente com o passar do tempo, sofrendo as devidas modificações que a adéque às necessidades do consumidor.

\section{Público celíaco}

Conforme Kamioka, Stedefeldt e Domene (2013) a Doença Celíaca (DC) é considerada uma enteropatia de origem genética, a qual origina geralmente no período da infância do indivíduo.

Essa doença é caracterizada pela intolerân- 
cia permanente ao glúten do trigo e às proteínas similares do centeio e da cevada, a mesma causa alterações no metabolismo, atrofia da mucosa intestinal e má absorção de nutrientes pelo organismo.Ainda para Kamioka Kamioka, Stedefeldt e Domene (2013), a DC pode se apresentar sob três formas: clássica e assintomática.

A Forma clássica consiste naquela qual se inicia nos primeiros anos de vida, apresentando sintomas como: distensão abdominal, irritabilidade, diminuição do tecido celular subcutâneo, atrofia da musculatura glútea, diarreia crônica, vômitos, anorexia e déficit de crescimento.

A forma não clássica manifesta- se mais tardiamente, apresentando manifestações isoladas, como constipação intestinal, problemas com esmalte dentário, artralgia ou artrite, osteoporose, esterilidade, baixa estatura, anemia por deficiência de ferro e epilepsia associada à calcificação intracraniana.

$\mathrm{Na}$ forma assintomática, a doença se encontra em latência, o indivíduo não apresenta problemas intestinais, porém pode vir a desenvolver a doença caso adote uma dieta excessiva em glúten.

Conforme as considerações de Kamioka, Stedefeldt e Domene (2013), o único tratamento efetivo é realizado de uma dieta rigorosa, restrita em glúten, quantidades pequenas podem não causar prejuízos para a maioria dos pacientes, mas podem causar importantes danos aos mais sensíveis.

O glúten está incluso no grupo de glicoproteínas das prolaminas; insolúvel em água, é responsável pela textura de massas, bolo e pães. Presente em alguns cereais, como trigo, a cevada, a aveia e o centeio, pode causar uma lesão tissular em indivíduos sensíveis e levar à doença. Alimentos variados presentes na dieta do brasileiro, como pães, bolos, bolachas, macarrão, salgados, pizzas, bebidas alcoólicas, embutidos e temperos industrializados, podem conter glúten na sua composição.

Em se tratando dos restaurantes, percebe-se que os mesmos representam, muitas vezes, perigo ao portador da DC, pois, segundo Ribeiro (2010), as chances de contaminação cruzada em restaurantes durante o preparo de cocção são muito altas, pois é comum a prática de cozinhar vários tipos de alimentos em um mesmo utensílio.
Em complemento à isso, para Ribeiro (2010):

A observância à dieta não constitui prática de fácil execução, especialmente em decorrência da contaminação dos alimentos, da incorreta discriminação da presença ou não do glúten em alimentos industrializados, custo da dieta e falta de conhecimento. Pacientes assintomáticos e aqueles que têm pouco conhecimento sobre sua doença são geralmente os que menos aderem a dieta. Infere-se ainda que, uma outra dificuldade na observância à dieta, seja a de que os alimentos que contém glúten estão presentes frequentemente no cardápio do ocidental. (Ribeiro, 2010, p.17).

Em complemento à isso, para Ribeiro (2010) existem uma infinidade de preocupações dos sujeitos portadores de DC, entre as quais pode-se citar: a obrigação de todo o tipo de rótulos alimentares, comer pão sem glúten, ser capaz de comer em um restaurante, cozinhar e planejar refeições sem glúten, planejar e tirar férias, ser capaz de comer com a família e amigos, falta de variedade na dieta deles e medo de que suas crianças desenvolvam a doença.

Entretanto, alguns avanços no sentido de se prover melhores e mais seguras informações alimentares aos celíacos tem ocorrido nos últimos anos. Em se tratando da cidade de Porto Alegre, foi aprovado, no ano de 2015, o projeto de lei ${ }^{\circ}$ $11.808^{2}$, o qual obriga restaurantes, bares, lanchonetes, confeitarias e congêneres a informarem, aos consumidores, a presença de glúten nos alimentos que comercializam. A referida lei também determina o fornecimento de merenda escolar adequada a alunos portadores da doença que frequentam a rede municipal de ensino.

Nesse sentido, parece possível a compreensão de que, apesar dos desafios que ainda se fazem presentes nas restrições alimentares dos portadores da doença celíaca, exemplos de boas prá-

2 PORTO ALEGRE. Câmara Municipal de Porto Alegre. Câmara promulga lei que obriga comércio a informar presença de glúten no cardápio. Porto Alegre. 2015. Disponível em <http://www2.camarapoa.rs.gov.br/default.php?reg=24424\&p_ secao=56\&di=2015-05-21 > Acesso em 10 nov. 2017. 
ticas e iniciativas sobre este tema tornam-se cada vez mais freqüentes na sociedade, a partir de uma perspectiva de atendimento às necessidades específicas e políticas de inclusão nos mais variados níveis.

\section{Metodologia}

Para este trabalho foi adotado o método de Estudo de caso, com a técnica de pesquisa de entrevista padronizada, aplicada junto com amostra de sujeitos portadores de DC. Conforme Yin (2010, p. 24) na obra Estudo de Caso - Planejamento e Métodos, "o estudo de caso é usado em muitas situações, para contribuir ao nosso reconhecimento dos fenômenos individuais, grupais, organizacionais, sociais, políticos e relacionados."

O objetivo geral é ajudar os pesquisadores a lidar com algumas das questões mais difíceis que são comumente negligenciadas pelos textos de pesquisa disponíveis. Como esforço de pesquisa, o estudo de caso contribui, de forma inigualável, para a compreensão que temos dos fenômenos individuais, organizacionais, sociais e políticos. Não surpreendentemente, o estudo de caso vem sendo uma estratégia comum de pesquisa na psicologia, na sociologia, na ciência política, na administração, no trabalho social e no planejamento (YIN, 2010).

Em resumo, o estudo de caso permite uma investigação para se preservar as características holísticas e significativas dos eventos da vida real, tais como ciclos de vida individuais, processos organizacionais e administrativos, mudanças ocorridas em regiões urbanas, relações internacionais e a maturação de alguns setores.

A visão mais apropriada dessas estratégias diferentes é pluralística. Pode- se utilizar cada estratégia por três propósitos: exploratório, descritivo ou explanatórios (YIN, 2010). O que diferencia as estratégias não é a hierarquia, mas três outras condições. No tipo de questão de pesquisa proposto, na extensão de controle que o pesquisador tem sobre eventos comportamentais efetivos e nos graus de enfoque em acontecimentos históricos em oposição a acontecimentos contemporâneos.
A estratégia de estudo de caso, começa com uma lógica de planejamento, uma estratégia que deve ser priorizada quando as circunstâncias e os problemas de pesquisas são apropriados, em vez de um comprometimento ideológico que deve ser seguido não importando quais sejam as circunstâncias.

\section{Definição dos sujeitos da pesquisa}

Para a seleção dos sujeitos da pesquisa (público celíaco) observaram-se os seguintes critérios:

\section{a) Localização}

Todos os sujeitos estão localizados residem no RS;

\section{b) Condição salutar}

Todos os sujeitos são portadores da Doença Celíaca.

\section{c) Associativismo}

Todos os sujeitos são membros da Associação.

\section{Coleta de dados}

A coleta de dados compreendeu duas etapas: contato telefônico com os gestores da Associação, e aplicação de formulário virtual de pesquisa junto ao grupo no Facebook.

\section{Contato telefônico}

Foi estabelecido contato telefônico com a Associação, visando identificar os responsáveis pelas operações. Após esse primeiro contato, foram realizadas as seguintes ações:

a) organização do instrumento online de pesquisa, disponível em: https://www.onlinepesquisa.com/s/097e5ea

b) solicitação para participar do Grupo do Facebook Celíacos Sngc do RS, disponível em: https://www.facebook.com/search/ top/?q=cel\%C3\%ADacos\%2Fsgnc\%20do\%20rs

c) postagem do link do formulário de coleta no grupo para obtenção de respostas dos seus respectivos membros. 


\section{Apresentação e análise dos dados e resultados}

Conforme exposto na Metodologia, a pesquisa foi aplicada com amostra de 43 participantes do Grupo Virtual da SNGC/RS, entre os dias 18 de Setembro 03 de Outubro de 2017. O instrumento de coleta continha questões abertas e fechadas. Segue abaixo o demonstrativo dos principais resultados obtidos com a aplicação do formulário virtual.

\section{Apresentação dos resultados}

Com o objetivo de melhor evidenciar o conteúdo das respostas, os dados obtidos serão dispostos sob a forma de tabelas, quadros e representações gráficas, tal como será apresentado a seguir.

Tabela 1 - Questão 1: Qual a sua idade?

\begin{tabular}{|c|c|c|}
\hline \multicolumn{1}{|c|}{ Faixa etária } & 8 & Percentual \\
\hline 21 a 30 anos & 15 & $34,6 \%$ \\
\hline 31 a 40 anos & 11 & $25,5 \%$ \\
\hline 41 a 50 anos & 9 & $20,9 \%$ \\
\hline 51 a 60 anos & $\mathbf{4 3}$ & $\mathbf{1 0 0 \%}$ \\
\hline Total & & \\
\hline
\end{tabular}

Fonte: Elaborado pela autora

Tabela 2 - Questão 2: Qual a faixa etária em que foi diagnosticada sua intolerância ao glúten - DC?

\begin{tabular}{|c|c|c|}
\hline Faixa etária & Quantidade & Percentual \\
\hline 0 a 10 anos & 3 & $7 \%$ \\
\hline 11 a 20 anos & 4 & $9,3 \%$ \\
\hline 21 a 30 anos & 11 & $25,6 \%$ \\
\hline 31 a 40 anos & 13 & $30,2 \%$ \\
\hline Acima de 40 anos & 12 & $27,9 \%$ \\
\hline
\end{tabular}

Fonte: Elaborado pela autora.

Segue abaixo o Gráfico 1, visando ilustrar esses percentuais obtidos através da questão 02.

Gráfico 1 - Percentuais Questão 2

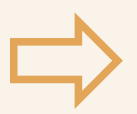

Fonte: Elaborado pela autora.

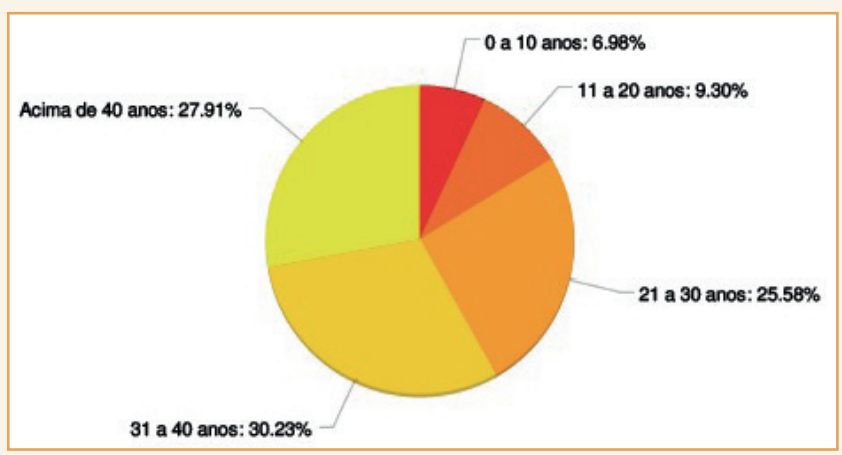


Tabela 3 - Questão 3: Você tem confiança em consumir alimentos que se dizem próprios para DC?

\begin{tabular}{|c|c|c|}
\hline Respostas & Quantidade & Percentual \\
\hline Plenamente & 13 & $30,2 \%$ \\
\hline Parcialmente & 16 & $37,2 \%$ \\
\hline Não Tenho Confiança & 1 & $2,3 \%$ \\
\hline Outros & 13 & $30,2 \%$ \\
\hline Total & 43 & $100 \%$ \\
\hline
\end{tabular}

Fonte: Elaborado pela autora.

Com base na tabela 3, foi elaborado o Gráfico 2, conforme segue:

Gráfico 2 - Questão 3 do instrumento de coleta

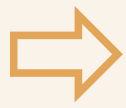

Fonte: Elaborado pela autora

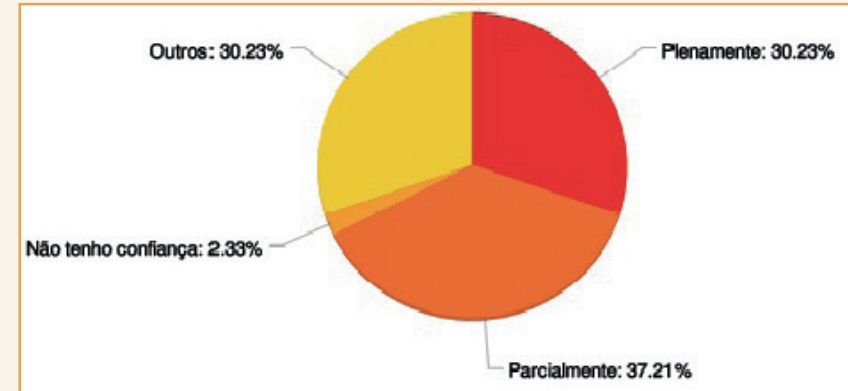

Nessa questão, era possível ainda complementar as respostas, sendo que a compilação das principais incidências estão transcritas literalmente conforme o quadro 1.

\section{Quadro 1 - Respostas abertas Questão 3 (continua)}

Incidências de respostas abertas

- As informações nas rotulagens, muitas vezes contêm informações que não condizem com a realidade;

- Primeiro verifico com os fabricantes para garantir que não há contaminação;

- Infelizmente nossa lei não é rigorosa o suficiente para entenderem a diferença do contem glúten e o não contém glúten;

- Porque não sabemos como realmente são feitos, se controlam os insumos (possuem declarações ou análises), a alimentação dos colaboradores;

- Não confio totalmente nas marcas as quais produzem outros produtos que contenha gluten, pois tenho medo de contaminação cruzada;

- Ainda há muito desconhecimento sobre o que é glúten, seus riscos, contaminação cruzada;

\section{Quadro 1 - Respostas abertas Questão 3 (conclusão)}

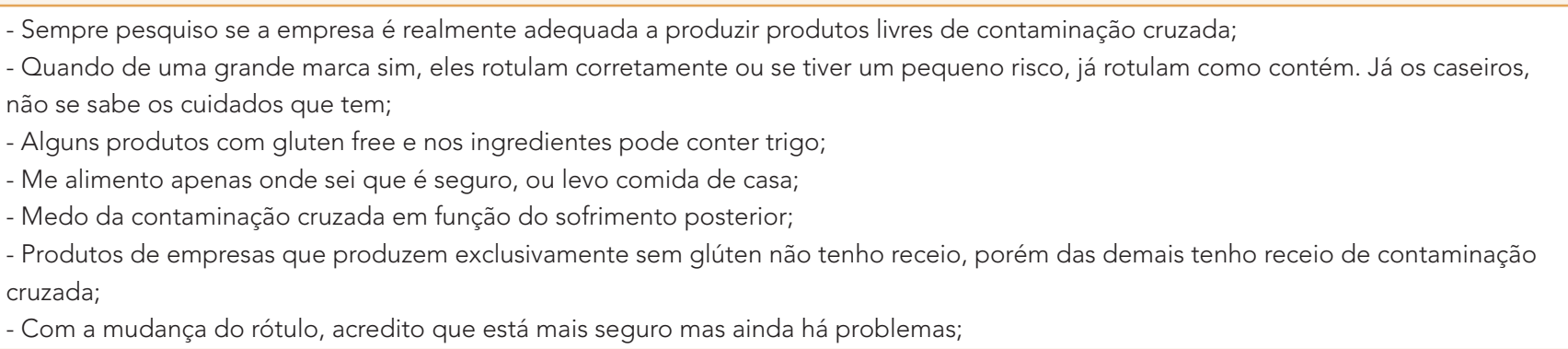


Tabela 4 - Questão 4 Em sua opinião, as alternativas dos restaurantes atendem as suas necessidades de dieta sem glúten?

\begin{tabular}{|c|c|c|}
\hline \multicolumn{1}{|c|}{ Respostas } & Quantidade & Percentual \\
\hline Plenamente & 0 & $0 \%$ \\
\hline Parcialmente & 12 & $27,9 \%$ \\
\hline Não atendem & 16 & $37,2 \%$ \\
\hline Outros & 15 & $34,9 \%$ \\
\hline Total & $\mathbf{4 3}$ & $\mathbf{1 0 0 \%}$ \\
\hline
\end{tabular}

Fonte: Elaborado pela autora.

Com base na tabela 4, foi elaborado o Gráfico 3, conforme segue:

Gráfico 3 - Questão 4 do instrumento de coleta

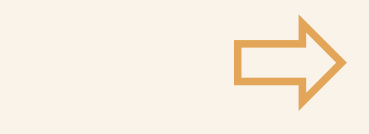

Fonte: Elaborado pela autora.

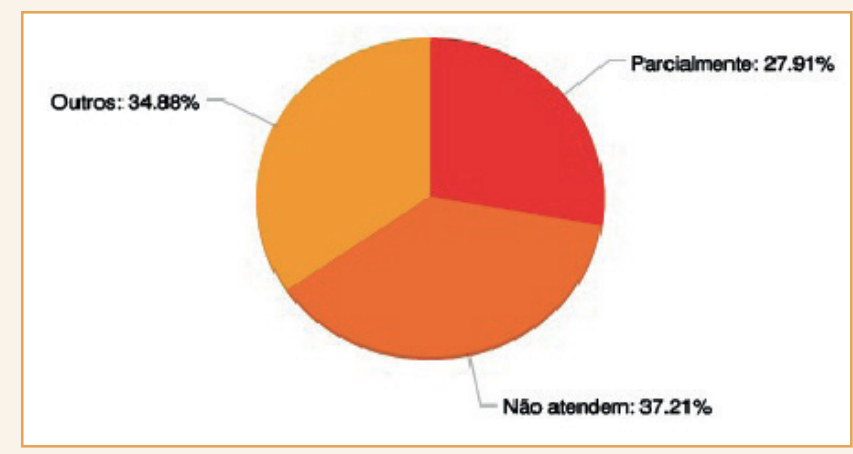

Nessa questão, era possível ainda complementar as respostas, sendo que a compilação das principais incidências estão transcritas literalmente conforme o quadro 2.

\section{Quadro 2 - Respostas abertas Questão 4}

- Poucas opções e não são confiáveis;

- São muito poucos os restaurantes que cuidam sobre a contaminação e, quando o fazem, temos poucas opções;

- Não tem cardápio, e os que têm não confio plenamente;

- Muitos não querem trabalhar com produtos sem glúten, pela contaminação cruzada;

- Cozinha exclusiva;

- A maior parte dos estabelecimentos não conhecem a Doença Celíaca ou encaram o não consumo de glúten como uma dieta da moda, não sabendo, absolutamente nada, a respeito da contaminação cruzada;

- Muito difícil encontrar restaurante com cardápio e cozinha adequados;

- consta no cardápio, porém não é servido;

- A maioria dos cozinheiros não tem o conhecimento necessário;

- Muitos não sabem nem o que é celíaco;

- São poucos os estabelecimentos que servem alimentos seguros para celíacos;

- Ainda são poucos restaurantes que atendem às necessidades para DC, em locais que não são exclusivos para dietas como DC existem pouquíssimas opções e nem sempre seguras e aos finais de semana é mais complicado, quase nenhum abre;

- A contaminação cruzada infelizmente é muito comum em restaurantes que não são exclusivamente sem glúten;

- Parcialmente, porque não sabemos os temperos que são usados nos alimentos, podemos colocar comida "sem glúten" no prato, mas sofrermos pela contaminação cruzada;

- Cuidados como não usar amaciante na carne poderiam ser evitados. 
Tabela 5 - Questão 5: Com que frequência costuma fazer suas refeições em restaurantes?

\begin{tabular}{|c|c|c|}
\hline Respostas & Quantidade & Percentual \\
\hline Todos os dias & 3 & $7 \%$ \\
\hline 1 a 3 vezes por semana & 7 & $27,9 \%$ \\
\hline 3 a 5 vezes por semana & 4 & $9,3 \%$ \\
\hline Menos de 1 vez por semana & 17 & $39,5 \%$ \\
\hline Outros & 12 & $27,9 \%$ \\
\hline Total & 43 & $100 \%$ \\
\hline
\end{tabular}

Fonte: Elaborado pela autora

Com base na tabela 5, foi elaborado o Gráfico 4, conforme segue:

Gráfico 4 - Questão 5 do instrumento de coleta

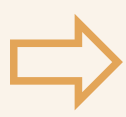

Fonte: Elaborado pela autora.

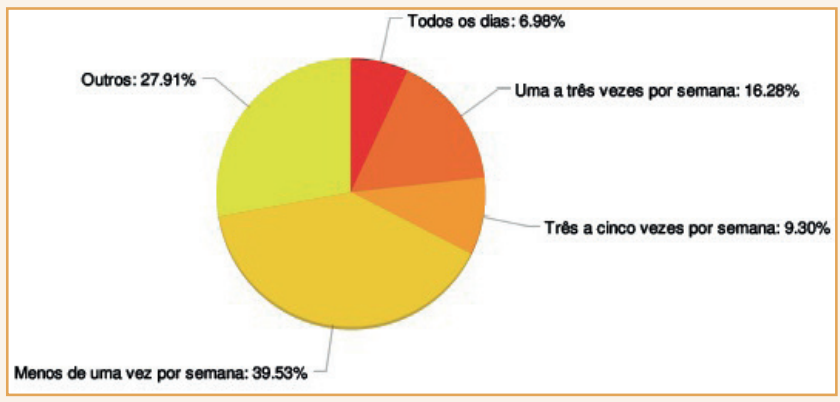

Nessa questão, era igualmente possível complementar as respostas, sendo que a compilação das principais incidências estão transcritas literalmente conforme o quadro 3.

\section{Quadro 3 - Respostas abertas Questão 5}

\section{Incidências de respostas abertas}

- Raramente faço refeições fora de casa;

- Menos de 1x por mês devido poucas opções sem contaminação;

- Minha comida feita por mim é $100 \%$ garantida;

-Poucas vezes por medo e falta de opções, pois a maioria dos estabelecimentos que servem alimentos sem glúten tem horários e dias restritos de atendimento;

- Nunca;

- Poucas vezes por falta de opções seguras;

-1 vez por ano;

- Nenhuma pois não há restaurante por perto para minha filha 100 \% garantido;

- Uma vez por mês, sem local próprio e quando tem, preço abusivo;

- Raramente;

- Somente quando não há outra alternativa. Medo de contaminação cruzada;

- Sempre evito. Faço minha própria comida e só eventualmente vou a restaurantes. 
Tabela 6 - Questão 6: Classifique, segundo sua avaliação, os itens que seguem sobre os restaurantes que oferecem opções sem glúten que frequentas

\begin{tabular}{|c|c|c|c|c|c|c|c|}
\hline QUESTÃO / INCIDÊNCIA & 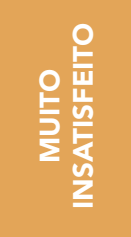 & 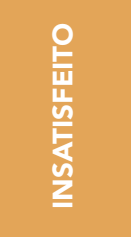 & 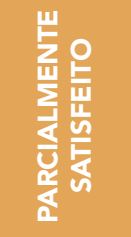 & 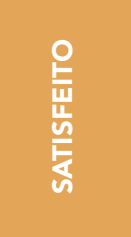 & 을 $\frac{0}{\frac{11}{5}}$ & 造齿 & 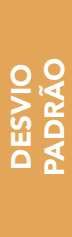 \\
\hline Preço & $\begin{array}{c}7 \\
(16,28 \%)\end{array}$ & $\begin{array}{c}10 \\
(23,26 \%)\end{array}$ & $\begin{array}{c}16 \\
(37,21 \%)\end{array}$ & $\begin{array}{c}10 \\
(23,26 \%)\end{array}$ & 0 & 2,67 & 1,02 \\
\hline Qualidade dos pratos & 0 & $\begin{array}{c}7 \\
(16,28 \%)\end{array}$ & $\begin{array}{c}21 \\
(48,84 \%)\end{array}$ & $\begin{array}{c}13 \\
(30,23 \%)\end{array}$ & $\begin{array}{c}2 \\
(4,65 \%)\end{array}$ & 3,23 & 0,78 \\
\hline Variedade dos Pratos & $\begin{array}{c}7 \\
(16,28 \%)\end{array}$ & $\begin{array}{c}19 \\
(44,19 \%)\end{array}$ & $\begin{array}{c}13 \\
(30,23 \%)\end{array}$ & $\begin{array}{c}2 \\
(4,65 \%)\end{array}$ & $\begin{array}{c}2 \\
(4,65 \%)\end{array}$ & 2,37 & 0,98 \\
\hline Confiabilidade das informações & $\begin{array}{c}4 \\
(9,30 \%)\end{array}$ & $\begin{array}{c}12 \\
(27,91 \%)\end{array}$ & $\begin{array}{c}17 \\
(39,53 \%)\end{array}$ & $\begin{array}{c}8 \\
(18,60 \%)\end{array}$ & $\begin{array}{c}2 \\
(4,65 \%)\end{array}$ & 2,81 & 1,01 \\
\hline Atendimento & $\begin{array}{c}1 \\
(2,33 \%)\end{array}$ & $\begin{array}{c}7 \\
(16,28 \%)\end{array}$ & $\begin{array}{c}16 \\
(37,21 \%)\end{array}$ & $\begin{array}{c}16 \\
(37,21 \%)\end{array}$ & $\begin{array}{c}3 \\
(6,98 \%)\end{array}$ & 3,30 & 0,91 \\
\hline
\end{tabular}

Fonte: Elaborado pela autora.

Tabela 7 - Questão 7: Assinale o seu nível de concordância com as afirmações que seguem

\begin{tabular}{|c|c|c|c|c|c|c|c|}
\hline QUESTÃO / INCIDÊNCIA & 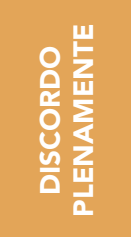 & 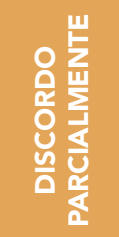 & 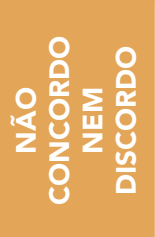 & 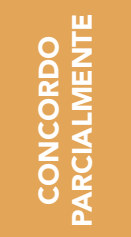 & 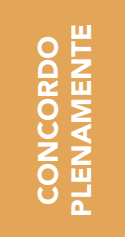 & 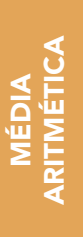 & 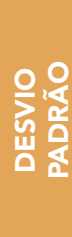 \\
\hline $\begin{array}{l}\text { A falta de opções de restaurantes me obriga a sair de } \\
\text { minha dieta celíaca }\end{array}$ & $\begin{array}{c}29 \\
(67,44 \%)\end{array}$ & $\begin{array}{c}1 \\
(2,33 \%)\end{array}$ & $\begin{array}{c}3 \\
(6,98 \%)\end{array}$ & $\begin{array}{c}7 \\
(16,28 \%)\end{array}$ & $\begin{array}{c}3 \\
(6,98 \%)\end{array}$ & 1,93 & 1,44 \\
\hline $\begin{array}{l}\text { Já recebi informações equivocadas sobre composição } \\
\text { de pratos em restaurantes; }\end{array}$ & $\begin{array}{c}1 \\
(2,33 \%)\end{array}$ & $\begin{array}{c}2 \\
(4,65 \%)\end{array}$ & $\begin{array}{c}3 \\
(6,98 \%)\end{array}$ & $\begin{array}{c}10 \\
(23,26 \%)\end{array}$ & $\begin{array}{c}27 \\
(62,79 \%)\end{array}$ & 4,40 & 0,98 \\
\hline $\begin{array}{l}\text { O atendimento e as opções para o público DC } \\
\text { melhoraram ao longo dos últimos } 05 \text { anos. }\end{array}$ & 0 & $\begin{array}{c}1 \\
(2,33 \%)\end{array}$ & $\begin{array}{c}5 \\
(11,63 \%)\end{array}$ & $\begin{array}{c}17 \\
(39,53 \%)\end{array}$ & $\begin{array}{c}20 \\
(46,51 \%)\end{array}$ & 4,30 & 0,77 \\
\hline $\begin{array}{l}\text { Sou bem atendido em virtude de minha } D C \text { toda vez } \\
\text { que vou à um restaurante; }\end{array}$ & $\begin{array}{c}13 \\
(30,23 \%)\end{array}$ & $\begin{array}{c}12 \\
(27,91 \%)\end{array}$ & $\begin{array}{c}8 \\
(18,60 \%)\end{array}$ & $\begin{array}{c}9 \\
(20,93 \%)\end{array}$ & $\begin{array}{c}1 \\
(2,33 \%)\end{array}$ & 2,37 & 1,20 \\
\hline $\begin{array}{l}\text { Acredito que deveria existir um projeto de lei que } \\
\text { aborde necessidade de melhor atenção à pessoas } \\
\text { com DC e restaurantes; }\end{array}$ & $\begin{array}{c}1 \\
(2,33 \%)\end{array}$ & 0 & $\begin{array}{c}1 \\
(2,33 \%)\end{array}$ & $\begin{array}{c}3 \\
(6,98 \%)\end{array}$ & $\begin{array}{c}38 \\
(88,37 \%)\end{array}$ & 4,79 & 0,71 \\
\hline
\end{tabular}

Fonte: Elaborado pela autora.

Nessa questão, era igualmente possível complementar as respostas, sendo que a compilação das principais incidências estão transcritas literalmente conforme o quadro 4. 


\section{Quadro 4 - Respostas abertas Questão 7 (continua)}

\section{Incidências de respostas abertas}

\section{- Para servir um celíaco, tudo tem que ser separo! Cozinha, utensílios.}

Muitos pratos podem ser substituídos por amido de milho, mas a preparação tem que ser feita na hora. Isso dificulta e encarece para os estabelecimentos.

- Em POA já existe lei que obriga a informação contém/não contem glúten. Porém nada relacionado a cuidados no manejo. - NORMALMENTE SOU BEM ATENDIDA QUANDO VOU A UM ESTABELECIMENTO QUE TEM OPÇÃO SG, COMO HAMBURGUERIAS, CAFETERIAS E ALGUNS RESTAURANTES. MAS SE VOU NUM ESTABELECIMENTO QUE NÃO SEI SE TEM OPÇÃO SG, MUITAS VEZES AS INFORMAÇÕES NÃO SE ENCONTRAM, TEM MUITA CONFUSÃO AINDA NO QUE SERIA "SEM GLÚTEN".

- Falta esclarecimentos sobre os cuidados para uma alimentação segura

-Existe uma Lei em Porto Alegre, republicada em julho de 2017 da obrigatoriedade de aviso nos cardápios sobre a presença ou ausência de glúten. Entra em vigor em 180 dias.

-A maioria dos funcionários de restaurantes não sabe dizer se os itens do cardápio têm glúten, e isso deveria ser algo básico em qualquer estabelecimento que trabalha com comida. Os lugares que têm opção para celíacos são um pouco mais preparados, contudo são caros. Infelizmente, manter uma dieta sem glúten, ou seja, cuidar da saúde, é pra quem tem dinheiro.

-Viajo muito e observo que poucas pessoas se preocupam com isso. Muitos não sabem o que é doença celíaca, confundem com lactose. Isso acontece em quase todo o Brasil.

- Tenho um filho de 12 anos que também é portador de DC, sempre que saímos ele tenta descobrir se a possibilidade de contaminação, na maioria das vezes as pessoas nem escutam e passam informações absurdas.

- A região que moro (interior do Rio Grande do Sul) a questão da alimentação para DC é muito restrita. Quase inexistente. Na verdade na cidade onde moro não existe um restaurante específico. Daí a dúvida em consumir alguma coisa, devido a contaminação cruzada. Em viagens para centros maiores sempre fui muito bem servida.

- Além de celíaca sou intolerante a lactose. Tenho que cuidar em dobro o que os restaurantes oferecem.

- Em alguns restaurantes, os atendentes não sabem o que é glúten, em outros, não fazem ideia do que é contaminação cruzada. Em alguns restaurantes as pessoas nem sabem o que compõem os pratos. Tu pergunta se tem glúten nos alimentos e a pessoa fala que não. Ai tu insiste na pergunta e descobre q tem glúten. Tipo strogonoff. Tem pessoas que engrossam o molho com farinha de trigo. Tu perguntas e a pessoa diz q não. Ai tu insiste e diz q tu não podes comer e tem que esclarecer a pergunta e perguntar pra cozinheira. Ai ela vem com cara de brava e diz q não. Ai tu pergunta e por que o molho está grosso. Ai ela responde q usou farinha de trigo. Isso é irritante. A gente ainda passa por chata. Acho que deveria ter uma formação para todos trabalhadores de restaurante pra evitar esse constrangimento.

OBS: a falta de opções nos restaurantes não me obriga a sair da dieta, mas muitas vezes como o que possivelmente não tem glúten e tenho contaminação cruzada.

\section{Quadro 4 - Respostas abertas Questão 7 (conclusão)}

-Nos últimos anos melhorou bastante, mas ainda há muito desconhecimento e confusão em restaurantes não exclusivos. E em muitos não há sequer opções. Devido às contaminações e falta de conhecimento acabo indo somente nos restaurantes específicos para restrições alimentares.

- Na maioria das vezes não sabem o que é doença celíaca, glúten, etc. Confundem glúten com lactose. De uma forma geral não sabem do que estão falando e acham que é "frescura".

- É bem complicado em todos os casos, porque restaurantes especializados além de poucos, não tem um valor tão acessível. Aliás, os produtos sem glúten não são tão acessíveis de um modo geral, locais e financeiramente falando, nos restaurantes 'normais' não podemos ter certeza se há contaminação cruzada devido aos temperos utilizados, que as vezes o garçom não sabe responder. É difícil encontrar produtos de boa qualidade e melhores especificações sobre o produto, muitos lugares nem sabem direito o que significa isso, o que é a doença ou até mesmo o glúten em si.

- Experiências são muitas, mas a maioria acha que o problema é farinha. Sempre é necessário citar todos os ingredientes de cada prato para que se tenha certeza absoluta.

- A falta de paciência é algo corriqueiro; 


\section{Análise de dados}

Em sequência a apresentação dos resultados do item anterior, serão destacados, a partir do presente momento, os principais pontos acerca das incidências de respostas que se vinculam diretamente à proposta deste trabalho.

A questão 01 assinala, primeiramente, para a faixa etária dos respondentes, evidenciando que a maioria dos referidos $(60,3 \%)$ encontra-se entre 31 a 50 anos. Em consonância com a questão 01, a questão 02 busca identificar em qual faixa etária os respondentes descobriram sua condição de portadores de Doença celíaca. Nessa questão, chama a atenção o fato de que a grande maioria dos respondentes $(83,7 \%)$ descobriu a sua condição apenas após o início da vida adulta, que assinala para uma realidade em que o diagnóstico desta doença nas fases iniciais da vida ainda seja um desafio para se prover melhor qualidade de vida aos portadores da DC.

$\mathrm{Na}$ questão 03, a qual tensionava o debate para o nível de confiança dos respondentes enquanto consumidores de produtos específicos para celíacos, foi possível observar apenas um terço dos entrevistados possui plena confiança nesses produtos, ao passo que para a maioria, há que se buscar outros meios para se assegurar a veracidade das informações prestadas nos rótulos desses produtos. A contaminação cruzada $^{3}$ também aparece como uma das principais preocupações dos entrevistados.

Nessa mesma linha, quando indagados, através da questão 04 , sobre a oferta de restaurantes para atendimento do público com DC, nenhum dos respondentes sinalizou que o mesmo ocorre de forma plena, assinalando que são poucos os restaurantes que estão devidamente habilitados para realizar esse atendimento. Foi igualmen-

\footnotetext{
3 A contaminação cruzada é uma transferência de traços ou partículas de glúten de um alimento para outro alimento, diretamente ou indiretamente. A contaminação cruzada pode ocorrer na área de manipulação de alimentos, mas também pode ocorrer durante o plantio, colheita, armazenamento, beneficiamento, industrialização e no transporte e comercialização desse produto. Disponível em: Disponível em: < www. riosemgluten.com/contaminacao_cruzada_por_gluten.htm Acesso em 10/11/2017
}

te sinalizado que são pouco variados os cardápios em restaurantes que oferecem opções ao celíaco, e que, mesmo assim, ainda não existe confiança plena de que os produtos sejam realmente livres de contaminação.

As incidências de respostas obtidas com a questão 05 refletem justamente o cenário identificado pela questão 04 , sinalizando que, em virtude das dificuldades e poucas opções de oferta, estes usuários passam a utilizar menos os serviços de restaurantes. Cerca de 39,5 \% dos entrevistados informa que faz refeições em restaurantes menos de 1 vez por semana, com a justificativa de que há muito risco de contaminação cruzada, e que a confiança é muito maior quando se acompanha e se realiza o preparo de suas próprias refeições.

A questão 06 procurava traçar um panorama geral da avaliação dos entrevistados sobre os restaurantes que são frequentados por eles, ainda que em reduzido número de vezes. Foram utilizadas as variáveis preço, qualidade e variedade dos pratos, a confiabilidade das informações e o atendimento. Com base nisso, identificou-se, em linhas gerais, que os principais aspectos positivos sinalizados foram a qualidade dos pratos $(30,23 \%$ satisfeitos) e o atendimento, com 37,21\% dos respondentes alegando estarem satisfeitos.

Já como destaque negativo, constatou-se a variedade dos pratos, com $60,47 \%$ dos respondentes insatisfeitos ou muito insatisfeitos e a confiabilidade das informações, com 37,21\% assinalado insatisfação ou muita insatisfação com este quesito, o que está diretamente em acordo com as incidências de respostas advindas das questões anteriores.

Outro fator que chama a atenção é o de que, nas 05 categorias analisadas, os pontos neutros, em que os respondentes sinalizam não estarem nem satisfeitos nem insatisfeitos, aparecem com consideráveis incidências, todas elas acima dos $30 \%$, com maior destaque para o item que contempla a qualidade dos pratos, com $48,84 \%$ do total de respostas.

Por fim, a sétima e última questão buscava identificar o nível de concordância dos entrevistados acerca de questões importantes sobre a adequação dos restaurantes ao público com DC. Com base na apresentação dos resultados desta ques- 
tão, é possível destacar, primeiramente, que a falta de opções observada nos restaurantes não se constitui num empecilho à manutenção da dieta celíaca dos respondentes, visto que, conforme já observado, muitos recorrem à outros recursos, como a produção própria dos seus alimentos, e a realizar a maioria de suas refeições em casa. Outro fator que se destaca, novamente, é o relato de experiências prévias deste público com informações equivocadas por parte dos restaurantes, o que poderia se constituir numa das principais causas de os mesmos evitarem utilizar este tipo de estabelecimento.

Entretanto, apesar desse contexto, constata-se que as impressões por parte destes usuários assinalam que os serviços dos restaurantes para atender ao público com DC, em geral, tiveram uma melhoria nos últimos 05 anos, o que, caso se mantenha, poderá configurar um cenário futuro de gradativas evoluções nas problemáticas descritas anteriormente.

Ao final da análise, a maior incidência comum de respostas dos entrevistados diz respeito à necessidade em se haver um projeto de lei (que aprimore aspectos da preexistente Lei $n^{\circ} 11.808$ ), que promova maior normatização dos restaurantes no que concerne aos produtos e serviços voltados aos celíacos, que envolva, inclusive, procedimentos e cuidados no manejo dos alimentos e formação de recursos humanos especializados para atender a este público.

Esta sugestão de incremento do projeto de lei poderia ser um importante passo em direção à uma melhoria constante no atendimento às demandas alimentares do público celíaco. Aliado a esta questão, a oferta de programas de treinamento de recursos humanos para atuação e atendimento específico aos clientes com restrições ao glúten também se configurariam como exemplos de boas práticas. Uma revisão dos processos de preparos e utilização dos utensílios das refeições nos restaurantes seria igualmente necessária, na medida em que reduziria os riscos de contaminação cruzada e ofereceria opções alimentares mais confiáveis e seguras aos clientes com restrições ao glúten.

Retomando o primeiro objetivo específico proposto para este trabalho, o qual consistia em identificar, a partir da visão dos respondentes da pesquisa, as principais fragilidades e fortalezas da prestação de serviços em A\&B para dietas com restrição ao glúten, pode-se constatar que o mesmo foi atingido a partir das respostas abertas das questões 03, 04 e 07, as quais evidenciam que as principais fragilidades seriam o cenário que ainda aponta para dificuldades no tocante à disposição de informações mais claras sobre os produtos e pratos específicos para celíacos. O risco de contaminação cruzada também aparece como um dos principais pontos negativos nesse processo, sendo que o mesmo poderá ocorrer em virtude da falta de preparo dos profissionais e por questões de infraestrutura dos restaurantes. Como pontos favoráveis, ressalta-se que mais de $77 \%$ dos entrevistados consideraram que o atendimento e as opções para o público DC melhoraram nos últimos 05 anos, que poderá sinalizar para um cenário de gradativa evolução acerca deste tema.

O segundo objetivo, o qual consistia em caracterizar o nível de confiança dos usuários sobre estes serviços foi atingido a partir das questões 03 e 04, 05 e 07, uma vez que identificou que ainda existe muito pouca confiança plena em que os pratos os quais se dizem livres de glúten sejam realmente $100 \%$ seguros. Como justificativas para esse baixo nível de confiança, os usuários relatam suas experiências prévias negativas com questões dessa ordem, o que poderia servir como explicação, conforme apontado na questão 05, para o fato de que muitos deles acabam optando por realizar o preparo de suas próprias refeições.

Já o terceiro e último objetivo específico, o qual se tratava de propor possíveis melhorias acerca do cenário analisado, foi atingido a partir das sugestões pontuadas que envolvem a atualização da Lei $n^{\circ} 11.808$, a melhoria na formação de recursos humanos especializados e a revisão dos processos de preparo e utilização de utensílios das refeições próprias para celíacos.

Em se tratando do objetivo geral, que buscava identificar de que forma os portadores de DC avaliam a oferta dos cardápios de restaurantes para sua restrição alimentar no tocante às variáveis: preço, qualidade e variedade dos pratos, confiabilidade das informações e atendimento, observa-se que o mesmo foi atingido especialmente a 
partir das questões 06 e 07. Com base nisso, identificou-se, em linhas gerais, que os principais aspectos positivos sinalizados pelos entrevistados foram a qualidade dos pratos (30,23\% satisfeitos) e $\mathrm{o}$ atendimento, com $37,21 \%$ dos respondentes alegando estarem satisfeitos.

Em se tratando das avaliações negativas, constatou-se a variedade dos pratos, com $60,47 \%$ dos respondentes insatisfeitos ou muito insatisfeitos e a confiabilidade das informações, com $37,21 \%$ assinalado insatisfação ou muita insatisfação com este quesito, o que está diretamente em acordo com as incidências de respostas advindas das questões anteriores.

\section{Considerações finais}

O presente trabalho possuiu o intuito de realizar uma análise junto aos membros da Associação, bem como a identificação, à partir do ponto de vista desse grupo de pessoas, dos pontos fortes e fracos dos restaurantes oferecidos no que compete às variáveis: preço, qualidade e variedade dos pratos, confiabilidade das informações e atendimento. A pesquisa foi executada entre os meses de setembro e outubro de 2017 com realização de um questionário online e registrando a coleta de dados baseada na resposta de 43 sujeitos portadores da restrição alimentar, o glúten.

O objetivo geral consistia em identificar de que forma os portadores de DC avaliam a oferta dos cardápios de restaurantes para sua restrição alimentar no tocante às variáveis: preço, qualidade e variedade dos pratos, confiabilidade das informações e atendimento.

Após a aplicação do instrumento de coleta de dados junto ao público alvo e a posterior análise de dados, foi possível identificar que o público com restrição ao glúten ainda não possui total confiança nas informações prestadas e na qualidade dos pratos servidos, em geral por experiências prévias negativas relativas à questões desta natureza. $O$ temor pela contaminação cruzada, acarretada, primordialmente em decorrência da falta de conhecimento e cuidado nos processos de preparo e manuseio dos utensílios também foi identificado como uma das principais razões pelas quais os consumidores celíacos ainda não se sentem plenamente seguros em relação ás ofertas alimentares específicas para sua condição.

Nesse sentido, o resultado da análise do instrumento de coleta apontou que, a partir da visão dos respondentes, os restaurantes em Porto Alegre que oferecem opções de pratos sem glúten, não são totalmente confiáveis, por terem a chamada contaminação cruzada.

Com a realização desta pesquisa, e do conhecimento obtido, foi possível constatar que o grupo de sujeitos entrevistados reforçam, em suas concepções, a importância que o pleno atendimento das necessidades alimentares dos usuários portadores da Doença Celíaca pode trazer, não somente para uma cidade, mas também para a expansão do conhecimento que abrange todo o grupo portador da Doença Celíaca, e que poderia, inclusive, trazer inúmeros benefícios à todos os novos diagnosticados com a mesma condição.

Percebe-se também, que apesar dos desafios, alguns avanços tem igualmente ocorrido, tanto pela melhoria no atendimento e na oferta de opções mais variadas, como pela inclusão do projeto lei que determina maior clareza nas informações dos itens alimentares que compõem cada prato nos restaurantes em Porto Alegre. Dessa forma, é notório que o referido tema encontra- se em constante discussão na sociedade atualmente.

Portanto, se todos nós, em nossa condição de cidadãos, portadores ou não da DC, dermos nossa contribuição para este debate crescente que promove uma melhoria nos processos de inclusão à públicos que possuem restrições alimentares, certamente poderemos observar, num futuro próximo, perceptíveis e constantes evoluções para a transformação de nossa sociedade num espaço mais voltado ao respeito às diferenças, as limitações e as individualidades de cada sujeito que a compõe. 


\section{Referências}

CANDIDO, Índio. VIERA, Elenara. Maître D Hotel: Técnicas de serviço. Caxias do Sul: Educs, 2002

CÂNDIDO, Índio Restaurante. Administração e Operacionalização. Caxias do Sul. Educs, 2010.

KAMIOKA, Gabriela Akemi; STEDEFELDT, Elke; DOMENE, Semíramis Martins Alvares. Doença Celíaca no município de São Paulo: a disponibilidade de um mercado específico. Nutrire Rev. Soc. Bras. Aliment. Nutr, p. 201-219, 2013

RIBEIRO, Caroline Moura Paz. Estudo de caso: um olhar sobre o cuidado na produção de alimentos permitidos ao portador (a) da doença celíaca. 2010.

TEICHMANN, Ione. Cardápios: Técnicas e Criatividade. Caxias do Sul: Educs, 2000

YIN, Robert K. Estudo de caso: planejamento e métodos. Tradução de Ana Maria Vasconcellos Thorell; consultoria de Cláudio Damacena. 4. ed. Porto Alegre, RS: Bookman, 2010. 248 p., il. 